\title{
Measuring the Effects of Unintended Pregnancy on Women's Quality of Life
}

\author{
Eleanor Bimla Schwarz ${ }^{1,4}$, Rachel Smith ${ }^{2}$, Jody Steinauer ${ }^{3}$, Matthew F. Reeves ${ }^{4}$, and Aaron \\ B Caughey ${ }^{3}$ \\ 1 Center for Research on Health Care, Division of General Internal Medicine, Department of Medicine, \\ University of Pittsburgh, Pittsburgh, PA. 15213 \\ 2School of Public Health, University of California, Berkeley; CA. 94704 \\ 3Department of Obstetrics, Gynecology, and Reproductive Sciences, University of California, San Francisco, \\ CA. 94143 \\ 4Department of Obstetrics, Gynecology, and Reproductive Sciences and Magee-Womens Research Institute, \\ University of Pittsburgh School of Medicine, Pittsburgh, PA. 15213
}

\section{Abstract}

Background-This study was conducted to assess the potential impact of an unintended pregnancy on women's quality of life.

Study design-We asked 192 non-pregnant women to report how they would feel if they learned they were pregnant using a visual analog scale (VAS), time-tradeoff (TTO), standard gamble (SG), and willingness-to-pay (WTP) metric.

Results-Women's anticipated responses to an unintended pregnancy varied widely. Using a VAS, $8 \%$ reported pregnancy would make them feel like they were dying. To avoid pregnancy, $28 \%$ were willing to trade time from the end of their life (TTO), $16 \%$ of women were willing to accept an immediate risk of death (SG), and $60 \%$ of women were willing to pay some amount of money (WTP). On average, women reported using the VAS, TTO, and SG metrics, that an unintended pregnancy would create a health utility state (where 0 represents death and 1 represents perfect health) of 0.487 , 0.992, and 0.997, respectively.

Conclusion-The anticipated effects of pregnancy on women's quality of life should be integrated into cost-effectiveness analyses of family planning services.

\section{Keywords}

Utility; QALY (Quality-adjusted life years); Decision Analysis; Cost effectiveness; unintended pregnancy

\footnotetext{
Corresponding author, and contact information for reprint requests: Eleanor Bimla Schwarz, MD, MS, University of Pittsburgh, Center for Research on Health Care, 230 McKee Place, Suite 600, Pittsburgh, Pa 15213, Phone (412) 586-9836, Fax (412) 692-4838, Email: schwarzeb@upmc.edu.

Publisher's Disclaimer: This is a PDF file of an unedited manuscript that has been accepted for publication. As a service to our customers we are providing this early version of the manuscript. The manuscript will undergo copyediting, typesetting, and review of the resulting proof before it is published in its final citable form. Please note that during the production process errors may be discovered which could affect the content, and all legal disclaimers that apply to the journal pertain.
} 


\section{Introduction}

Unintended pregnancy is common in the United States, where it is estimated that half of all pregnancies are unintended [1]. Contraceptive services, which are provided in the hopes of helping women avoid unintended pregnancy and abortion, have been shown to be cost-effective when method-related costs are compared to costs of abortion services [2-8]. However, such analyses ignore the potentially significant effect an unintended pregnancy may have on a woman's quality of life. As other preventive health services, which may compete with contraceptive services for limited public health dollars, are frequently evaluated using measures that incorporate the health service's impact on quality of life [9], it is important that evaluations of contraceptive services also consider effects on quality of life.

Quality-adjusted life years (QALYs) are frequently used in decision and cost-utility analyses to mathematically represent the impact on quality of life an intervention may have. This representation is useful when models are constructed to systematically analyze health-related choices and consequences. QALYs are calculated by combining empiric measures of utility values with time anticipated spent in a given health state. According to convention, utility values range from 0 to 1 , with 0 representing the state of death and 1 indicating a state "of perfect health." Utility values have been derived for many populations and disease states [10, 11]. Methods that have been commonly used to assess the utility of a health state include the visual analog scale [11], the time-trade-off metric [10], the standard-gamble metric [12], and the willingness-to-pay metric [13].

While efforts have been made to assess women's values regarding reproductive health services such as prenatal screening [7] and amniocentesis [4], most cost-effectiveness studies of contraceptive services [3-9] have focused on method-related costs, and costs of pregnancyrelated health services, without considering measures of personal utility or QALYs. One previous analysis of contraceptive services [8] that did consider QALYs reported a short-term disutility associated with an induced abortion of 0.0385 , which is equivalent to a utility value of 0.9615 (as disutility=1-utility). However, this utility was estimated using data "elicited from a convenience sample of female members of the research team and advisory panel using the time-tradeoff technique." [8] Therefore, the generalizability of these estimates is potentially limited. In addition, as an unintended pregnancy may adversely affect a woman's quality of life whether or not she chooses abortion, an empiric assessment of the value women place on avoiding unintended pregnancy (as opposed to simply avoiding an abortion) would be useful to future decision and cost-utility analyses.

In this study, we sought to estimate, in a diverse group of sexually active women who were trying not to become pregnant, the value placed on the health state of not being pregnant. To assess whether estimates of utility produced using time-tradeoff techniques are similar to estimates produced by other metrics, we measured the value women placed on not being pregnant using additional metrics commonly-used in the literature: a visual analog scale, the time trade-off metric previously used by Sonnenberg et al. [8], a standard gamble, and a willingness-to-pay metric.

\section{Methods}

We surveyed sexually active women who stated they were not currently pregnant or trying to become pregnant when they presented to three health centers in Pittsburgh, Pennsylvania, during the summer of 2006. These included the University of Pittsburgh student health clinic, a Planned Parenthood family planning clinic, and a hospital-based outpatient gynecology clinic. English-speaking women, aged 18 to 46 years, were asked by a research assistant using a recruitment script to complete self-administered questionnaires while they waited to see a 
clinician. Women who agreed to participate were given an information sheet that described the risks and benefits of participating in this anonymous survey. No compensation was supplied. This study was approved by the Institutional Review Boards of the University of Pittsburgh and the University of California, Berkeley.

The first portion of the questionnaire included 17 questions about socio-demographic and reproductive health information. Women who stated they were currently pregnant or trying to become pregnant were excluded from further analyses. Women were also asked "if you found out you were pregnant TODAY what would you most likely do?" Response options included (1) continue the pregnancy, planning to parent, (2) continue the pregnancy, planning for adoption, (3) have an abortion, and (4) don't know. The second portion of the questionnaire included 7 questions which aimed to empirically assess the utility value women place on avoiding unintended pregnancy using four methods that have been commonly used by decision scientists: a visual analog scale [14], time-trade off metric [15], standard gamble metric [10], and willingness-to-pay metric [16]. Women were asked to do thought experiments in which they envisioned a hypothetical situation in which they "learned today you were pregnant." They were then asked to use each of the value metrics to describe their response to that hypothetical pregnancy scenario.

Using a visual analog scale (VAS), women were asked to place a mark on a line to describe "How would you feel if you learned today you were pregnant?" The line's anchors were labeled on one end, "in perfect health," and on the other end, "as if I was dying." For the time-trade off metric (TTO), women were asked to imagine they were pregnant and then asked: "Imagine it was possible to magically not be pregnant if you gave up time at the end of your life. How much time would you be willing to give up at the end of your life in order to avoid having to be pregnant right now?" Women were then given 9 response options including: no time, 1 day, 2 days, 1 week, 1 month, 2 months, 3 months, 6 months, 1 year, or asked to specify an amount of time greater than one year. With a standard gamble (SG) metric, subjects are presented 2 alternatives: one that offers the possibility of perfect health but requires the subject face some risk of death, and an alternative which allows the subject to avoid a risk of death but will require the subject face imperfect health. For this standard gamble (SG) metric, women were asked: "Imagine it was possible to magically not be pregnant if you waved a magic wand. The only problem with this wand is that it sometimes kills people who wave it. What risk of death would you be willing to take in order to wave this wand and avoid having to be pregnant today?" Women were then offered 5 response options ranging from no risk of death to a $10 \%$ risk of death. For the willingness-to-pay metric (WTP), women were asked: "imagine it was possible to magically not be pregnant if you gave up an amount of money. How much money would you be willing to pay?" For the WTP metric, women were given 9 response options including: no money, $\$ 10, \$ 50, \$ 100, \$ 500, \$ 1,000, \$ 5,000, \$ 10,000$, or the option of writing in a value more than $\$ 10,000$.

To calculate utility values from women's responses on the VAS, we measured the distance on the VAS the woman marked from "as if I was dying" in $1 \mathrm{~mm}$ increments and divided it by the distance between the two anchors which was $12 \mathrm{~cm}$. In calculating the utility values from women's responses to the time-tradeoff (TTO) metric, we calculated the ratio of (LE - TTO)/ LE, where TTO was the time a woman reported being willing to trade from the end of her life to avoid currently being pregnant, and LE was her life expectancy as estimated using data from the CDC National Vital Statistics Reports (NVSR) [17]. As the life expectancies reported in the NSVR are recorded at 5-year intervals, we used linear interpolation to adjust for age and gender in estimating life expectancy at 1-year intervals. To calculate utility value from women's responses to the standard gamble (SG) metric, we calculated 1-p\%, where $p \%$ was defined as the "acceptable risk of immediate death" women reported using the survey instrument. We did not attempt to calculate utility values from responses to the willingness to 
pay (WTP) metric as there is no accepted algorithm for doing so. Histograms are used to display the distributions obtained using each of these metrics. We also report median, range, and mean utility values reported by all subjects using each metric.

We chose a sample size of at least 190 subjects to ensure that mean utility estimates would have a margin of error no greater than $7 \%$ at a 95 percent level of confidence. We used descriptive statistics to summarize demographic and reproductive information including: age, race, marital status, employment status, education, income, history of pregnancy, history of unwanted pregnancy, number of births, and number of abortions. All the subjects were currently sexually active. We also examined whether sexually active women who would consider abortion differed from those who would not by grouping women who stated they "didn't know" what they would do if faced with a pregnancy with those who stated they would "have an abortion" and grouping women who stated they would "plan to parent" with those who would "plan for adoption." We examined the relationship between these variables and visual analog scores, using Student's t-tests. Similarly, we examined the relationship between demographic and reproductive variables and responses to the VAS, TTO, SG, and WTP metrics using Chi-square tests and Fisher's exact tests. Finally, we used tetrachoric correlation [18, 19] to examine whether women provided similar responses using dichotomous versions of the utility metrics. Tetrachoric correlation statistics provide a way to separately quantify association and similarity of category definitions. The correlation coefficient produced using this method is interpreted the same way a Pearson's correlation coefficient would be: a value of +1 indicates perfect positive correlation, values $0.5-1$ are consider a "large" correlation and less than 0.3 as a small correlation. Negative numbers are used to indicate a negative correlation. When we created dichotomous versions of the utility metrics, we compared women who anticipated that an unintended pregnancy would in any way adversely affect their current health to those who stated that a pregnancy would have no effect on their current situation. All analyses were performed using Stata 9.0

\section{Results}

We recruited 219 sexually active women from June to September 2006. Eleven women who were pregnant, 9 who were trying to become pregnant, 4 women who completed less than half of the survey, and 3 women who were over 46 years of age were excluded. The demographic characteristics of the 192 women included in our study are presented in Table 1. Reproductive characteristics are reported in Table 2.

The proportion of women who indicated that learning they were pregnant today would adversely impact the quality of their life varied when different metrics were used (Table 3).

Using a visual analog scale, $8 \%$ of respondents reported a pregnancy would make them feel "like they were dying" and 6\% reported they anticipated they would feel "in perfect health" (Fig. 1). When these responses were converted to utilities, the mean utility reported by respondents using the VAS was 0.489 .

When women were asked to use the time-tradeoff metric, we found $25 \%$ of women were willing to trade some time from the end of their life (range 1 day to "any amount"). As shown in Fig. 2 , the distribution of utility values obtained using the time-trade-off metric was highly skewed. The median utility value reported using the TTO metric was 1.0 with a range from 0.830 to 1.0 .

Using the standard gamble metric, we found $16 \%$ of women were willing to accept an immediate risk of death to avoid an unintended pregnancy. However, again the distribution of responses was highly skewed (Fig. 3). Using the WTP metric, 60\% of women indicated a willingness to pay some amount of money to avoid currently being pregnant (Fig. 4). The 
median amount of money women were willing to pay to avoid currently being pregnant was $\$ 100$ (range 0 to "any amount"). Women with higher annual incomes were not more likely to report they were willing to pay larger amounts of money to avoid currently being pregnant $(\mathrm{p}=0.10)$.

With all metrics, women who reported that if they found out today they were pregnant they would most likely "have an abortion" were more likely to indicate pregnancy would adversely affect their quality of life than women who stated they would plan to parent, plan for adoption or didn't know (Table 3, column 2). Using the VAS, among women who would have an abortion, $26 \%$ reported that a pregnancy would make them feel like they were dying, compared to $0 \%, 1 \%$ and $8 \%$ among women who would plan to parent, plan for adoption, or didn't know, respectively. Using the TTO and SG, utility values placed on avoiding pregnancy were considerably higher among women who would consider abortion than among those who would not. With the WTP metric we found that among women who reported they would most likely have an abortion, $94 \%$ were willing to pay some amount of money to avoid currently being pregnant, compared to $83 \%$ of women who would plan for adoption $72 \%$ of women who didn't know what they would do if faced with an unintended pregnancy and $37 \%$ of women who would plan to parent.

With most metrics used, women's marital status was related to how much an unintended pregnancy would impact their quality of life; women who were married were less likely to indicate that pregnancy would adversely affect their quality of life (Table 3, column 3). In addition, women's race/ethnicity was associated with how much an unintended pregnancy would impact their quality of life. In general, white women placed more value on avoiding pregnancy than black women (Table 3, column 4). Age, income, having a college education, employment status, gravidity, and parity did not have a consistent impact on measures of utility placed on avoiding pregnancy.

Analysis of dichotomized responses with tetrachoric correlation showed significant correlation between responses indicating that pregnancy would adversely affect current health provided with each of four metrics (Table 4). Responses provided using the VAS, SG, and WTP metrics were highly correlated. However, responses provided using the VAS and TTO were less likely to correlate in indicating that pregnancy would adversely affect a woman's current health as many women who used the VAS to indicate that a pregnancy would adversely affect their current state of health were not willing to trade any time from the end of their life to avoid the negative impact they perceived a pregnancy would entail.

\section{Discussion}

When we surveyed an ethnically diverse group of 192 sexually active women about the value they place on avoiding pregnancy, we found that most (94\%) women reported they would feel in less than perfect health if they learned today they were pregnant and over half of women were willing to pay some amount of money to avoid learning today they were pregnant. While the estimates of disutility generated varied depending whether the VAS, TTO, or SG metrics were used, women who used one metric to indicate pregnancy would pose a disutility were more likely to also indicate disutility using other metrics. The utility women placed on avoiding pregnancy varied significantly by race, marital status and whether or not the woman would consider abortion, but less so by income or educational attainment. However, in almost all cases, women reported becoming pregnant would result in greater disutility than was previously reported when Sonnenberg et al [8] studied the anticipated impact of an abortion on a woman's quality of life. 
This study builds on prior work by prospectively examining the value a diverse group of women place on avoiding pregnancy. However, the study does have some limitations. The survey was conducted in a single metropolitan area, and the data collected do not allow us to examine whether responses varied by site. The survey was self-administered and it is possible that some women did not understand the "thought experiments" they were asked to engage in. Further, the women who participated in this study were not currently pregnant, and their responses about how a pregnancy would impact their quality of life may differ from the responses they would provide when truly faced with an unintended pregnancy. Variables describing women's reproductive history were self-reported, and while the use of an anonymous survey can diminish social acceptability biases, self-reported abortion histories are notoriously unreliable. In addition, value placed on avoiding pregnancy may differ for younger teens, and for women in other parts of the world. Future studies should therefore collect data from women who are younger than 18 years and women in other geographic locations. Finally, future studies should explore other dimensions of why an unintended pregnancy might adversely impact a woman's quality of life, such as concern about exacerbating a health condition or risk of domestic violence.

The results of this study emphasize that not all women seeking contraception place the same value on avoiding pregnancy. While it is important that this information be incorporated into cost-effectiveness analyses, these results also emphasize the importance of clinicians eliciting women's attitudes towards an unintended pregnancy. For women who indicate that an unintended pregnancy would adversely impact their quality of life, contraceptive counseling should be offered in the same way that other preventive health measures (that patients may not actively seek out on their own) are provided.

Overall, the findings of this study indicate that an unintended pregnancy has measurable adverse effects on women's quality of life that can and should be incorporated into costeffectiveness analyses of family planning services. However, further research is needed to elucidate which metrics yield the most valid estimates of the utility women place on avoiding unintended pregnancy. In addition, in order to convert measured utilities into QALYs, future studies will need to examine how long women with an unintended pregnancy would spend in a given health state.

\section{Acknowledgements}

We thank Doug Oman, $\mathrm{PhD}$ and Mitch Creinin, MD for their guidance. Dr. Schwarz was supported by a career development award from the National Institute of Child Health and Development (K23 HD051585-01).

\section{References}

1. Henshaw SK. Unintended pregnancy in the United States. Fam Plann Perspect 1998;30:24-29. 46. [PubMed: 9494812]

2. Blumenthal PD, Trussell J, Singh RH, et al. Cost-effectiveness of treatments for dysfunctional uterine bleeding in women who need contraception. Contraception 2006;74:249-258. [PubMed: 16904420]

3. Braunstein JB, Hausfeld J, Hausfeld J, London A. Economics of reducing menstruation with trimonthly-cycle oral contraceptive therapy: comparison with standard-cycle regimens. Obstet Gynecol 2003;102:699-708. [PubMed: 14550999]

4. Caughey AB, Washington AE, Gildengorin V, Kuppermann M. Assessment of demand for prenatal diagnostic testing using willingness to pay. Obstet Gynecol 2004;103:539-545. [PubMed: 14990419]

5. Chiou CF, Trussell J, Reyes E, et al. Economic analysis of contraceptives for women. Contraception 2003;68:3-10. [PubMed: 12878280]

6. Koenig JD, Strauss MJ, Henneberry J, Wilson TG. The social costs of inadequate contraception. Int J Technol Assess Health Care 1996;12:487-497. [PubMed: 8840668] 
7. Kuppermann M, Nease RF, Learman LA, Gates E, Blumberg B, Washington AE. Procedure-related miscarriages and Down syndrome-affected births: implications for prenatal testing based on women's preferences. Obstet Gynecol 2000;96:511-516. [PubMed: 11004350]

8. Sonnenberg FA, Burkman RT, Hagerty CG, Speroff L, Speroff T. Costs and net health effects of contraceptive methods. Contraception 2004;69:447-459. [PubMed: 15157789]

9. Brisson M, Van de Velde N, De Wals P, Boily MC. The potential cost-effectiveness of prophylactic human papillomavirus vaccines in Canada. Vaccine 2007;25:5399-5408. [PubMed: 17561316]

10. Torrance GW. Measurement of health state utilities for economic appraisal. J Health Econ 1986;5:130. [PubMed: 10311607]

11. Stevens KJ, McCabe CJ, Brazier JE. Mapping between Visual Analogue Scale and Standard Gamble data; results from the UK Health Utilities Index 2 valuation survey. Health Econ 2006;15:527-533. [PubMed: 16389651]

12. van Osch SM, Stiggelbout AM. The construction of standard gamble utilities. Health Econ 2008;17:31-40. [PubMed: 17410521]

13. Olsen JA, Smith RD. Theory versus practice: a review of 'willingness-to-pay' in health and health care. Health Econ 2001;10:39-52. [PubMed: 11180568]

14. Robinson A, Loomes G, Jones-Lee M. Visual analog scales, standard gambles, and relative risk aversion. Med Decis Making 2001;21:17-27. [PubMed: 11206943]

15. van der Pol M, Shiell A. Extrinsic goals and time tradeoff. Med Decis Making 2007;27:406-413. [PubMed: 17585007]

16. King JT Jr, Tsevat J, Lave JR, Roberts MS. Willingness to pay for a quality-adjusted life year: implications for societal health care resource allocation. Med Decis Making 2005;25:667-677. [PubMed: 16282217]

17. Arias E. United States life tables, 2003. Natl Vital Stat Rep 2006;54:1-40. [PubMed: 16681183]

18. Fleming JS. TETCORR: a computer program to compute smoothed tetrachoric correlation matrices. Behav Res Methods 2005;37:59-64. [PubMed: 16097344]

19. Gunther A, Hofler M. Different results on tetrachorical correlations in Mplus and Stata--Stata announces modified procedure. Int J Methods Psychiatr Res 2006;15:157-166. [PubMed: 17019900] 


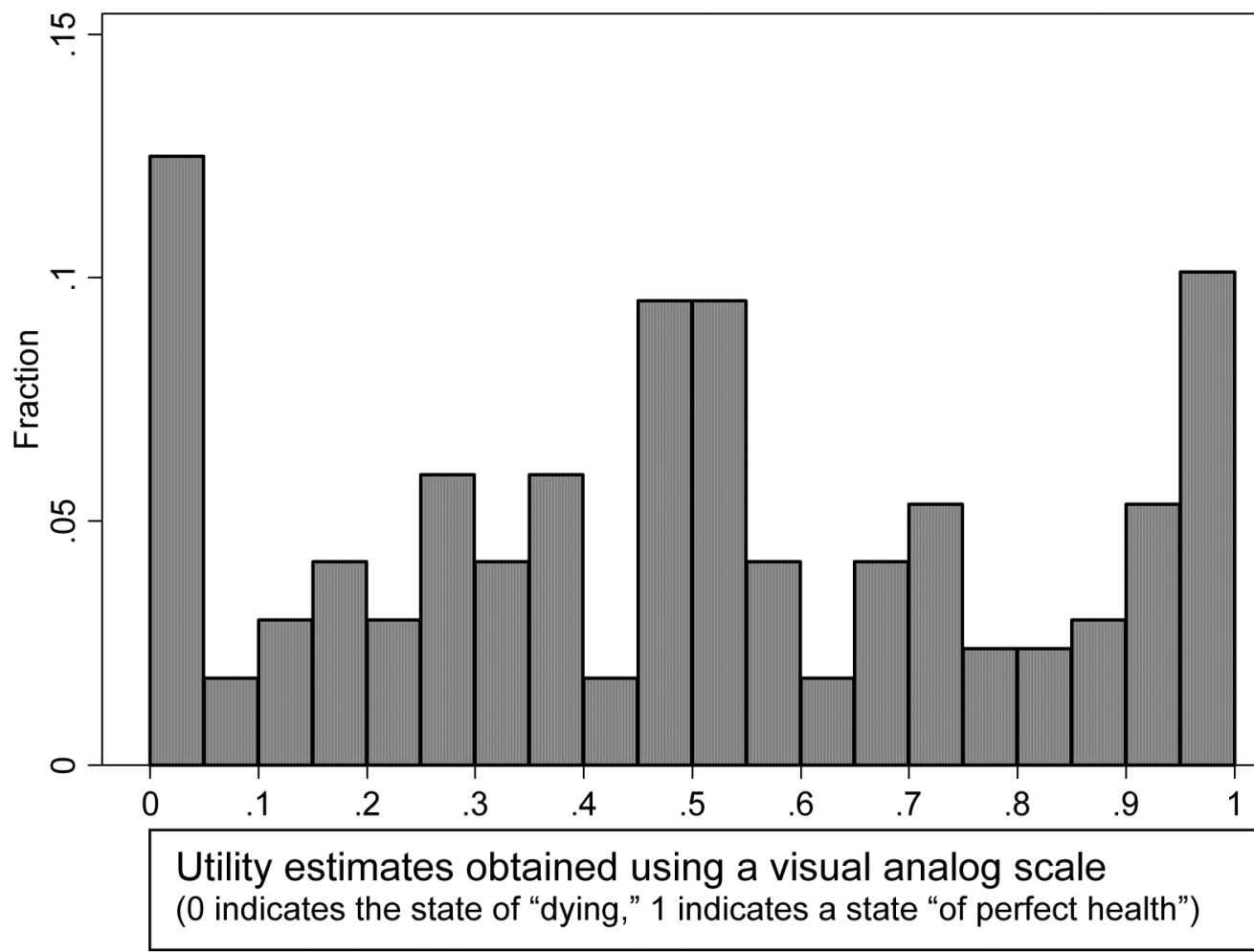

Fig. 1.

Fraction of population (or percent of respondents) reporting a given utility associated with unintended pregnancy as measured using a visual analog scale. 


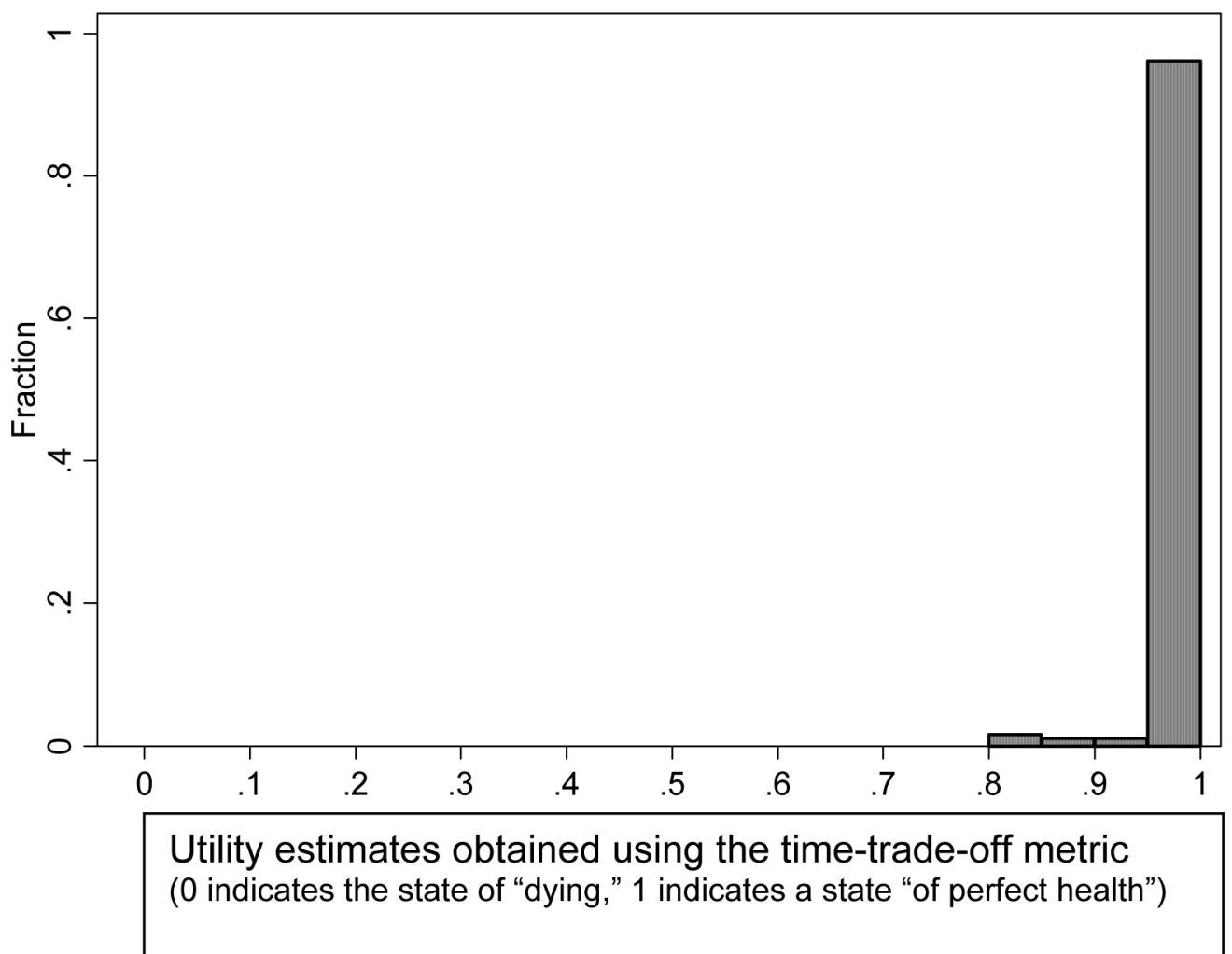

Fig. 2.

Fraction of population (or percent of respondents) reporting a given utility associated with unintended pregnancy as measured using the Time-Tradeoff metric. 


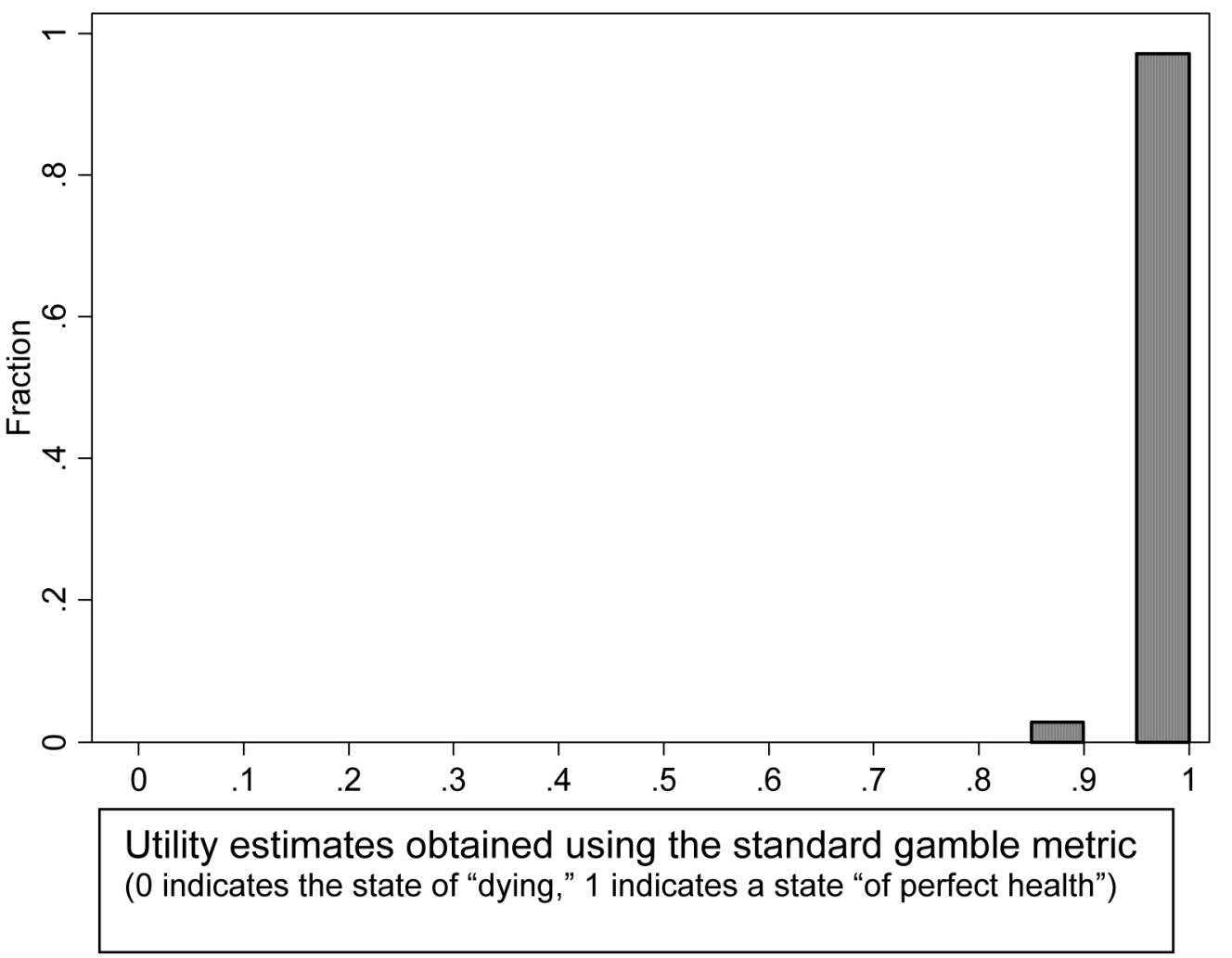

Fig. 3.

Fraction of population (or percent of respondents) reporting a given utility associated with unintended pregnancy as measured using the standard gamble metric. 


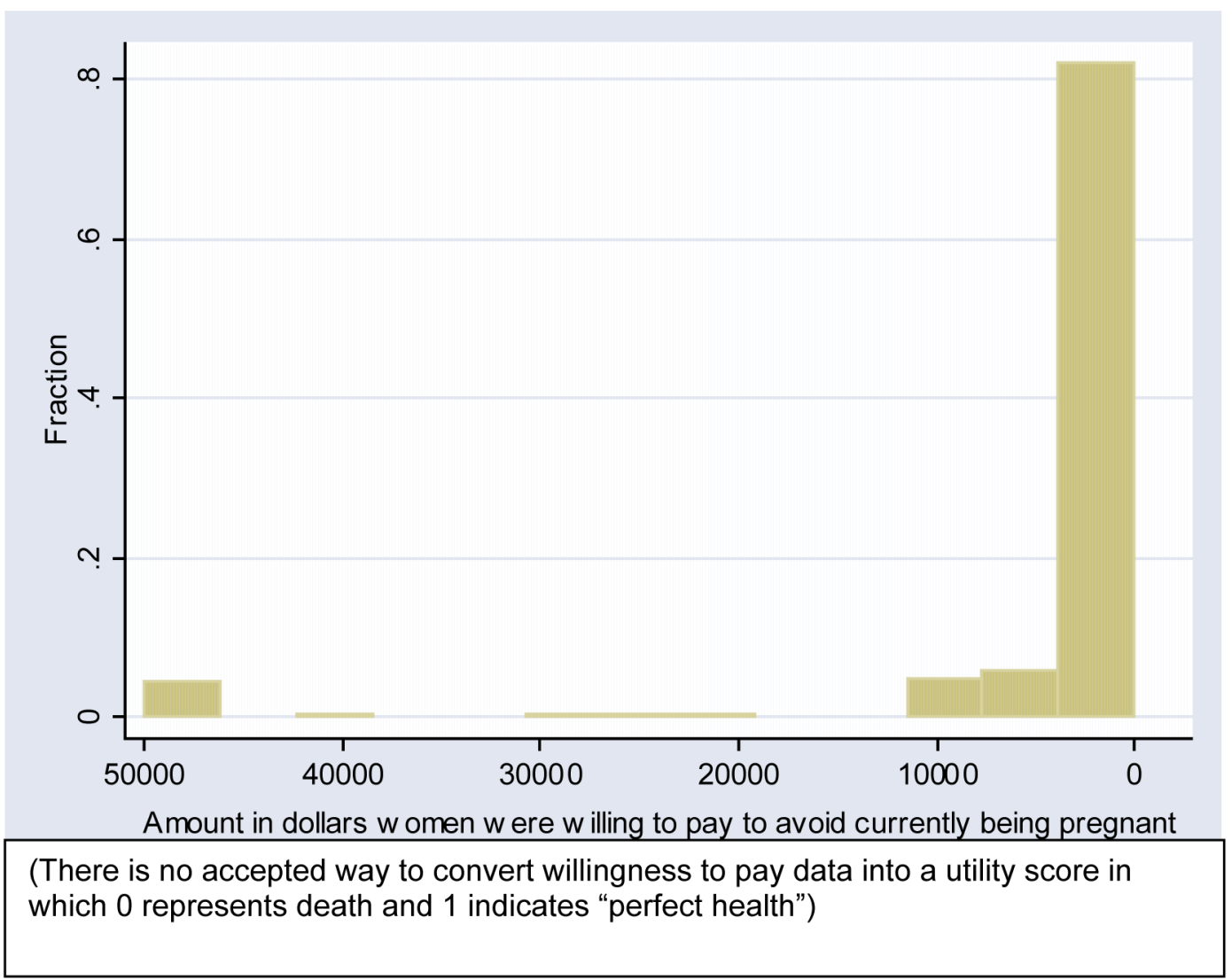

Fig. 4.

Distribution of amount of money women were willing to pay to avoid an unintended pregnancy. 
Table 1

Sociodemographic and reproductive characteristics of study participants

\begin{tabular}{|c|c|}
\hline Characteristic & Total $(\mathrm{N}=192)$ \\
\hline $\begin{array}{l}\text { Age, in years, mean (standard deviation) } \\
\text { median (range) }\end{array}$ & $\begin{array}{c}\text { No. (\%) } \\
25(6) \\
23(18-46)\end{array}$ \\
\hline $\begin{array}{l}\text { White } \\
\text { Black }\end{array}$ & $138(72)$ \\
\hline $\begin{array}{l}\text { Black } \\
\text { Latina }\end{array}$ & $\begin{array}{c}39(20) \\
1(1)\end{array}$ \\
\hline Asian & $2(1)$ \\
\hline Other/Mixed & $12(6)$ \\
\hline \multicolumn{2}{|l|}{ Marital status ${ }^{*}$} \\
\hline Never married & $95(45)$ \\
\hline Married & $16(8)$ \\
\hline Living as married & $53(28)$ \\
\hline Separated, divorced, or widowed & $12(6)$ \\
\hline \multicolumn{2}{|l|}{ Education } \\
\hline Middle school & $1(1)$ \\
\hline High school graduate & $35(18)$ \\
\hline Vocational school or some college & $92(48)$ \\
\hline College degree & $42(22)$ \\
\hline Graduate or professional degree & $22(11)$ \\
\hline \multicolumn{2}{|l|}{ Income $^{*}$} \\
\hline$<\$ 20,000$ & $93(48)$ \\
\hline$\$ 20,001-\$ 40,000$ & $31(16)$ \\
\hline$\$ 40,001-\$ 60,000$ & $21(11)$ \\
\hline$\$ 60,001-\$ 80,000$ & $9(5)$ \\
\hline$>\$ 80,001$ & $14(7)$ \\
\hline
\end{tabular}

* Marital status was not reported by 16 subjects, income was not known/reported by 24 women. 
Table 2

Reproductive characteristics of study participants

\begin{tabular}{|c|c|}
\hline Characteristic & Total $(\mathrm{N}=192)$ \\
\hline & No. $(\%)$ \\
\hline \multicolumn{2}{|l|}{ Reproductive history } \\
\hline Prior pregnancy & $65(34)$ \\
\hline Prior birth & $45(23)$ \\
\hline Prior abortion & $29(15)$ \\
\hline \multicolumn{2}{|l|}{ Method of contraception used at last sex } \\
\hline Hormonal & $131(68)$ \\
\hline Barrier & $91(47)$ \\
\hline Rhythm/Withdrawal & $31(16)$ \\
\hline Sponge/Spermicide & $6(3)$ \\
\hline Intrauterine device & $2(1)$ \\
\hline Lesbian & $5(3)$ \\
\hline None & $11(6)$ \\
\hline Desire to have a child in the future & $160(83)$ \\
\hline \multicolumn{2}{|l|}{ Opposed to abortion } \\
\hline No & $129(67)$ \\
\hline Yes & $48(25)$ \\
\hline Don't know & $15(8)$ \\
\hline \multicolumn{2}{|l|}{ If pregnant today would most likely } \\
\hline Plan to parent & $89(46)$ \\
\hline Plan for adoption & $6(3)$ \\
\hline Have an abortion & $39(20)$ \\
\hline Don't know & $58(30)$ \\
\hline
\end{tabular}


Schwarz et al.

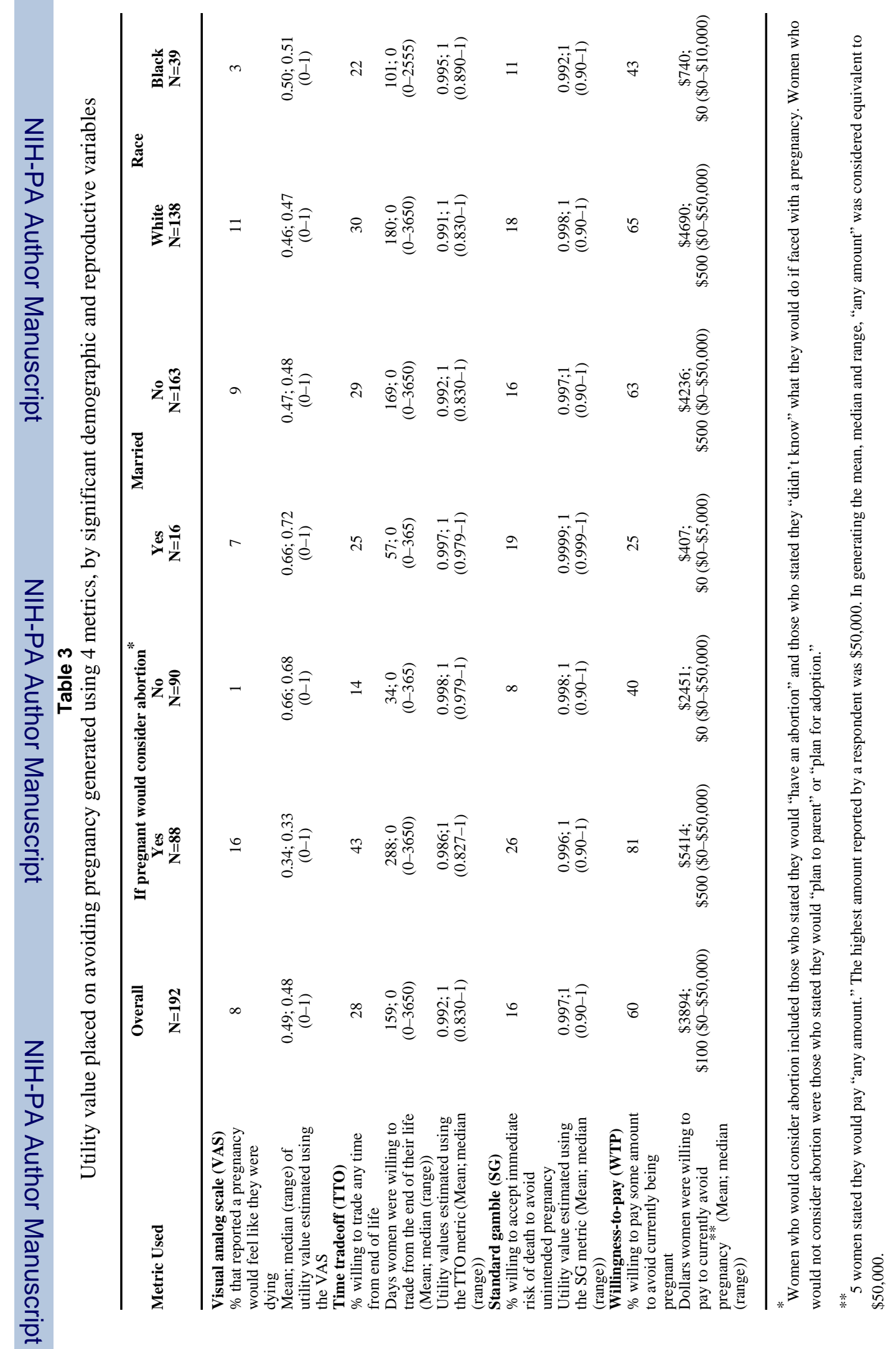

Contraception. Author manuscript; available in PMC 2009 September 1. 


\section{Table 4}

Tetrachoric correlation* between responses indicating pregnancy would adversely affect current health provided with each of four metrics

\begin{tabular}{|c|c|c|c|c|}
\hline & Time-tradeoff & Visual analog scale & Standard gamble & Willingness-to-pav \\
\hline Time-tradeoff & 1.00 & -- & -- & -- \\
\hline Visual analog scale & 0.16 & 1.00 & -- & -- \\
\hline Standard gamble & 0.78 & 1.00 & 1.00 & -- \\
\hline Willingness-to-pay & 0.84 & 1.00 & 0.59 & 1.00 \\
\hline
\end{tabular}

* Tetrachoric correlation statistics provide a way to separately quantify association and similarity of category definitions. The correlation coefficient produced using this method is interpreted as follows: a value of +1 indicates perfect positive correlation, values $0.5-1.0$ indicate a large correlation and less than 0.3 a small correlation. The dichotomous versions of the utility metrics presented here compare women who anticipated that an unintended pregnancy would in any way adversely affect their current health to those who stated that a pregnancy would have no affect on their current situation. All women who used the standard gamble and willingness to pay metrics to indicate that they anticipated a pregnancy would have some adverse impact on their present health indicated that pregnancy would adversely impact their health with the VAS. 